\title{
The level of C-erbB-2 in patients with esophageal and gastric cancers
}

\author{
@Serkan Cerrah ${ }^{1}$, @Salim Başol Tekin ${ }^{2}$ \\ ${ }^{1}$ Health Sciences University, Erzurum Regional Training and Research Hospital, Department of Gastroenterology, Erzurum, Turkey \\ ${ }^{2}$ Ataturk University, Depertment of Medical Oncology, Erzurum, Turkey
}

Cite this article as: Cerrah Si Tekin SB. The level of C-erbB-2 in patients with esophageal and gastric cancers. Anatolian Curr Med J 2021; 3(3); 208-213.

\begin{abstract}
Aim: In this study, we aimed to reveal the prevalence of c-erbB-2 expression in patients with gastric and esophageal cancers in the Eastern Anatolia Region and their relationships with pathologic parameters.

Material and Method: A total of 50 patients, 25 esophageal cancer and 25 gastric cancer patients, who were diagnosed and operated in three clinics at Atatürk University, School of Medicine (Internal Medicine, General Surgery, and Thoracic Surgery) between 2000-2007, were retrospectively included in the study. The parameters belonging to these cases, such as histologic type, differentiation degree, tumor invasion depth, and lymph node metastasis, were extracted from the pathology reports. We obtained the preparations from pathology laboratory archives and reexamined them. Those suitable for immunohistochemical stain were selected from the paraffin block archive and undergone to immunohistochemical process.

Results: We detected c-erbB-2 positivity in 6 (24\%) of 25 patients with esophageal cancer and 7 (\%28) of 25 patients with gastric cancer. The relationships between c-erbB-2 expression scores and the selected parameters were evaluated using the Chisquare test. Ultimately, we found no significant relationships between c-erbB-2 positivity and differentiation degree ( $\mathrm{p}=0.447)$, tumor invasion depth $(\mathrm{p}=0.067)$, and lymph node metastasis $(\mathrm{p}=0.461)$. Despite no statistical relationships, esophageal cancer cases with positive c-erbB-2 displayed noticeable features, such as lymph node involvement and well-differentiated tumors. In the cases with gastric cancer, there were no statistical relationships between c-erbB-2 positivity and the WHO classification $(\mathrm{p}=0.748)$, the Lauren classification $(\mathrm{p}=0.373)$, lymph node metastasis $(\mathrm{p}=0.629)$, tumor invasion depth $(\mathrm{p}=0.262)$, and differentiation degree $(\mathrm{p}=0.083)$. However, by the WHO classification, lymph node involvement and tubularity were noticeable features of all cases with c-erbB-2 positivity.

Conclusion: Larger and further studies are needed to more clearly observe the effect of C-erbB-2 expression on clinicopathological outcomes in gastric and esophageal cancers.
\end{abstract}

Keywords: C-erbB-2, gastric cancer, esophageal cancer

\section{INTRODUCTION}

Esophageal cancer is a disease that shows late symptoms and spreads rapidly throughout the esophagus. It is often difficult to be diagnosed early, and patients, unfortunately, apply to a physician late $(1,2)$. There are regional differences in esophageal cancer incidences; it is more prevalent in regions with low socioeconomic levels. Esophageal cancer is seen at a rate of $1.5 \%-2 \%$ among all cancer types and $7 \%$ among gastrointestinal cancers. It is frequently encountered in Iran, China, South Africa, the USA, Ceylon, Normandy, Britain, and the Eastern Anatolia Region in Turkey $(3,4)$. Tobacco and alcohol use, nitrosamines, zinc and molybdenum deficiencies, achalasia, tylosis characterized by hyperkeratosis of the palms and soles, caustic strictures, Plummer Winson's syndrome, and human papillomavirus play a role in the etiology of esophageal squamous cell cancer. Among the risk factors of esophageal adenocarcinoma are gastroesophageal reflux and Barrett's esophagus $(3,5)$.

On the other hand, stomach cancer is one of the most prevalent cancers; its incidence varies geographically. It is rather prevalent in Japan, Chile, Finland, Costa Rica, Colombia, Portugal, Russia, and Bulgaria. Western Europe, New Zealand, and Australia are the countries where it is less prevalent. Ranking first among gastrointestinal cancers in Turkey, it is placed fourth among all cancers. According to the Ministry of Health's latest statistics, stomach cancer ranks first in males and 
second in females in Erzurum (4). Among the reasons triggering gastric cancer development are environmental, genetic, and familial factors as well as helicobacter pylori and nutritional habits $(6,8)$.

So far, many laboratory methods have been investigated in terms of etiology, early diagnosis, prognosis, and follow-up in gastric and esophageal cancers. However, no marker that can be used to determine the diagnosis, follow-up, and prognosis specific for these cancers has yet been identified $(9,10)$. C-erbB-2 (HER-2/neu) is a protooncogene encoding a transmembrane glycoprotein with $185 \mathrm{kDa}$ molecular weight and 1255 amino acids, mapped on chromosome 17q21. Studies generally suggest that gastric cancer patients showing c-erbB-2 overexpression have a lower survival rate compared to patients who do not and that c-erB-2 overexpression is a poor prognostic factor $(11,12)$. In some studies performed with patients with esophageal adenocarcinoma, c-erbB-2 overexpression was suggested to be associated with poor prognosis (13). In another study carried out with esophageal squamous cell cancer patients, c-erB-2 positivity was presented to be a new prognostic factor (14).

Through an immunohistochemical study, we aimed to reveal the frequency of c-erbB-2 expression in esophagus and stomach cancers, which are frequently seen in Erzurum and its nearby regions, and its relationships with pathological parameters. Also, we evaluated its effectiveness as a prognostic factor.

\section{MATERIAL AND METHOD}

For the study, we obtained ethical approval from the Ethics Committee of School of Medicine, Atatürk University (Dated 12.15.2006; Session No: 8; Decision No: 40 ). A total of 50 patients (25 esophageal cancer and 25 gastric cancer patients), who were diagnosed and operated in three clinics at the School of Medicine, Atatürk University (Internal Medicine, General Surgery, and Thoracic Surgery) between 2000-2007, were retrospectively included in the study. We evaluated the demographic information and surgery findings from the case files. We extracted the data, such as histological type and differentiation degree, tumor invasion depth, lymph node metastasis, and presence of distant metastasis, from the pathology reports. We reexamined the ready-made preparations obtained from the preparation archive of the pathology laboratory. They were reclassified and rechecked by the WHO and Lauren classifications, and the results were confirmed. Preparations belonging to the cases were reexamined. Immunohistochemical examinations of those suitable for immunohistochemical staining were performed in the immunopathology unit of the Department of Pathology, School of Medicine, Atatürk University. We used 5-micrometer sections prepared from paraffin blocks for the immunohistochemical study.

We did the evaluation of the immunohistochemically applied c-erbB-2 antibody staining by examining the hematoxylin-Eosin-stained ready-made preparation and the c-erbB-2-stained preparation of each material together. Then, we evaluated positive staining for C-erbB-2 by precise membranous staining. Cytoplasmic staining was evaluated as negative immunoreactivity. While evaluating staining, we considered examining all tumor areas in the section. Membranous staining acuity was assessed by weak or intense complete membranous staining.

Accordingly, no staining in all of the tumoral areas was considered immunoreactivity negative (-) for c-erbB-2. The immunoreactivity for c-erbB-2 was considered +1 (positive) when there was a weak or intense complete membranous immunoreactivity in less than $10 \%$ of all tumor-containing areas or a partial (incomplete) immunoreactivity in more than $10 \%$ of the areas. When there was weak and complete membranous staining in more than $10 \%$ of all tumoral areas, the immunoreactivity was deemed +2 (positive) for c-erbB-2. Finally, immunoreactivity for c-erbB-2 was evaluated as +3 (positive), when more than $10 \%$ of all tumoral areas had severe and complete membranous staining.

\section{Statistical Analysis}

Data on patients with esophageal and gastric cancers are presented in separate Table 1 and Table 2. The relationships between c-erbB-2 expression scores and the selected parameters were evaluated using the Chi-square test. The cases with non-significant but remarkable results were also recorded. In all statistical analyses, the level of significance was accepted as 0.05 .

\section{RESULTS}

The mean age of the cases with esophageal cancer was $54.1 \pm 12.7$ (16-82) years. Among the cases, 16 (64\%) were males and $9(36 \%)$ were females. Neighboring tissues and distant metastases were not detected in any of the patients included in the study. It was found that 6 cases (24\%) had no lymph node metastasis of the tumor (stage N0), while 19 cases (76\%) had lymph node metastasis (stage N1) (Table 1). Ultimately, we found no significant relationships between c-erbB-2 positivity and differentiation degree $(\mathrm{p}=0.447)$, tumor invasion depth $(\mathrm{p}=0.067)$, and lymph node metastasis $(\mathrm{p}=0.461)$ (Table 1). Although there was no relationship between differentiation degree and the intensity of c-erbB-2 antibody staining, +2 and +3 (positive immunoreactivity) 
staining were seen only in well-differentiated tumors. Besides, c-erbB-2 positive immunoreactivity was seen only in cases with lymph node involvement despite no significant relationships. According to the intensity of staining assessed based on the membranous properties of the immunohistochemically applied c-erbB-2 antibody in the cases diagnosed with esophageal squamous cell carcinoma, 16 cases (64\%) were scored as 0 (negative), 3 cases (12\%) as +1 (negative), 5 cases (20\%) as +2 (positive), and 1 case (4\%) as +3 (positive) (Figures 1-4).

The mean age of patients with gastric cancer was $60 \pm 7.19$ (50-77) years. Eighteen (72\%) of the cases were males and 7 (28\%) were females. Of tumors, 6 (24\%) were corpus-located, 9 (36\%) were antrum-located, 6 (24\%) were cardia-located, 2 (8\%) were corpus+cardia-located, and $2(8 \%)$ were corpus+antrum-located. By the Lauren classification, 2 of the patients $(8 \%)$ were with diffusetype cancer, 19 (76\%) were with intestinal-type cancer, and $4(16 \%)$ were with mixed-type cancer. According to the WHO classification, $22(88 \%)$ cases were tubular and $3(12 \%)$ cases were considered as mucinous type as histopathological type. Distant metastasis was not detected in any of the patients included in the study.
Subtotal removal was performed in $6(24 \%)$ patients, and total gastrectomy was performed in 19 (76\%) patients. According to the intensity of staining assessed based on the membranous properties of the immunohistochemically applied c-erbB-2 antibody in the cases diagnosed with gastric adenocarcinoma, 15 cases $(60 \%)$ were scored as 0 (negative), 3 cases (12\%) as +1 (negative), 2 cases ( $8 \%$ ) as +2 (positive), and 5 cases $(10 \%)$ as +3 (positive) (Figures 5-8).

We could not reach significant relationships between c-erbB-2 positivity and differentiation degree $(p=0.083)$, tumor invasion depth $(\mathrm{p}=0.262)$, lymph node metastasis $(p=0.629)$, the Lauren classification $(p=0.373)$, and the WHO classification $(\mathrm{p}=0.748)$. There was also no significant relationship between histopathological subtype and c-erbB-2 antibody staining intensity. However, +2 and +3 (positive immunoreactivity) staining were seen only in tubular-type cancers by the WHO classification and only in intestinal-type cancers by the Lauren classification. Although there were no statistically significant relationships, c-erbB-2 positive immunoreactivity was found only in cases with lymph node involvement.

Table 1. The relationships between C-erbB-2 staining intensity and pathological parameters in cases with esophageal cancer

\begin{tabular}{|c|c|c|c|c|c|c|c|c|c|c|c|c|}
\hline \multirow{2}{*}{$\begin{array}{l}\text { Pathological } \\
\text { parameters }\end{array}$} & \multirow{2}{*}{ Groups } & \multirow{2}{*}{$\begin{array}{l}\text { Number of } \\
\text { cases }\end{array}$} & \multirow{2}{*}{$\%$} & \multicolumn{8}{|c|}{ C-erbB-2 staining intensity, number of cases, and percentages } & \multirow{2}{*}{$p$ value } \\
\hline & & & & - & $\%$ & $1+$ & $\%$ & $2+$ & $\%$ & $3+$ & $\%$ & \\
\hline \multirow{3}{*}{$\begin{array}{l}\text { Differentiation } \\
\text { degree }\end{array}$} & Poor & 1 & 4 & 1 & 4 & 0 & 0 & 0 & 0 & 0 & 0 & \multirow{3}{*}{0.447} \\
\hline & Moderate & 13 & 52 & 10 & 40 & 2 & 8 & 1 & 4 & 0 & 0 & \\
\hline & Good & 11 & 44 & 5 & 20 & 1 & 4 & 4 & 16 & 1 & 4 & \\
\hline \multirow{4}{*}{$\begin{array}{l}\text { Tumor invasion } \\
\text { depth }\end{array}$} & $\mathrm{T} 1$ & 4 & 16 & 4 & 16 & 0 & 0 & 0 & 0 & 0 & 0 & \multirow{4}{*}{0.067} \\
\hline & $\mathrm{T} 2$ & 7 & 28 & 4 & 16 & 2 & 8 & 1 & 4 & 0 & 0 & \\
\hline & T3 & 14 & 56 & 8 & 32 & 1 & 4 & 4 & 16 & 1 & 4 & \\
\hline & $\mathrm{T} 4$ & 0 & 0 & 0 & 0 & 0 & 0 & 0 & 0 & 0 & 0 & \\
\hline \multirow{2}{*}{$\begin{array}{l}\text { Lymph node } \\
\text { metastasis }\end{array}$} & None & 6 & 24 & 3 & 12 & 2 & 8 & 1 & 4 & 0 & 0 & \multirow{2}{*}{0.461} \\
\hline & Present & 19 & 76 & 13 & 52 & 1 & 4 & 4 & 16 & 1 & 4 & \\
\hline
\end{tabular}

Table 2. The relationships between C-erbB-2 staining intensity and pathological parameters in cases with gastric cancer

\begin{tabular}{|c|c|c|c|c|c|c|c|c|c|c|c|c|}
\hline \multirow{2}{*}{$\begin{array}{l}\text { Pathological } \\
\text { parameters }\end{array}$} & \multirow{2}{*}{ Groups } & \multirow{2}{*}{$\begin{array}{l}\text { Number } \\
\text { of Cases }\end{array}$} & \multirow{2}{*}{$\%$} & \multicolumn{8}{|c|}{ C-erbB-2 staining intensity, number of cases, and percentages } & \multirow{2}{*}{$p$ value } \\
\hline & & & & - & $\%$ & $1+$ & $\%$ & $2+$ & $\%$ & $3+$ & $\%$ & \\
\hline \multirow{3}{*}{$\begin{array}{l}\text { Differentiation } \\
\text { degree }\end{array}$} & Poor & 11 & 44 & 6 & 24 & 2 & 8 & 1 & 4 & 2 & 8 & \multirow{3}{*}{0.083} \\
\hline & Moderate & 8 & 32 & 6 & 24 & 0 & 0 & 0 & 0 & 2 & 8 & \\
\hline & Good & 6 & 24 & 3 & 12 & 1 & 4 & 1 & 4 & 1 & 4 & \\
\hline \multirow{4}{*}{$\begin{array}{l}\text { Tumor invasion } \\
\text { depth }\end{array}$} & $\mathrm{T} 1$ & 5 & 20 & 5 & 20 & 0 & 0 & 0 & 0 & 0 & 0 & \multirow{4}{*}{0.262} \\
\hline & $\mathrm{T} 2$ & 3 & 12 & 1 & 4 & 0 & 0 & 1 & 4 & 1 & 4 & \\
\hline & $\mathrm{T} 3$ & 17 & 68 & 9 & 36 & 3 & 12 & 1 & 4 & 3 & 12 & \\
\hline & $\mathrm{T} 4$ & 0 & 0 & 0 & 0 & 0 & 0 & 0 & 0 & 0 & 0 & \\
\hline \multirow{2}{*}{$\begin{array}{l}\text { Lymph node } \\
\text { metastasis }\end{array}$} & None & 2 & 8 & 2 & 8 & 0 & 0 & 0 & 0 & 0 & 0 & \multirow{2}{*}{0.629} \\
\hline & Present & 23 & 92 & 12 & 48 & 3 & 12 & 2 & 8 & 8 & 5 & \\
\hline \multirow{3}{*}{$\begin{array}{l}\text { Lauren } \\
\text { classification }\end{array}$} & Diffuse & 2 & 8 & 1 & 4 & 1 & 4 & 0 & 0 & 0 & 0 & \multirow{3}{*}{0.373} \\
\hline & Intestinal & 19 & 76 & 10 & 40 & 2 & 8 & 2 & 8 & 5 & 20 & \\
\hline & Mix & 4 & 16 & 4 & 16 & 0 & 0 & 0 & 0 & 0 & 0 & \\
\hline
\end{tabular}




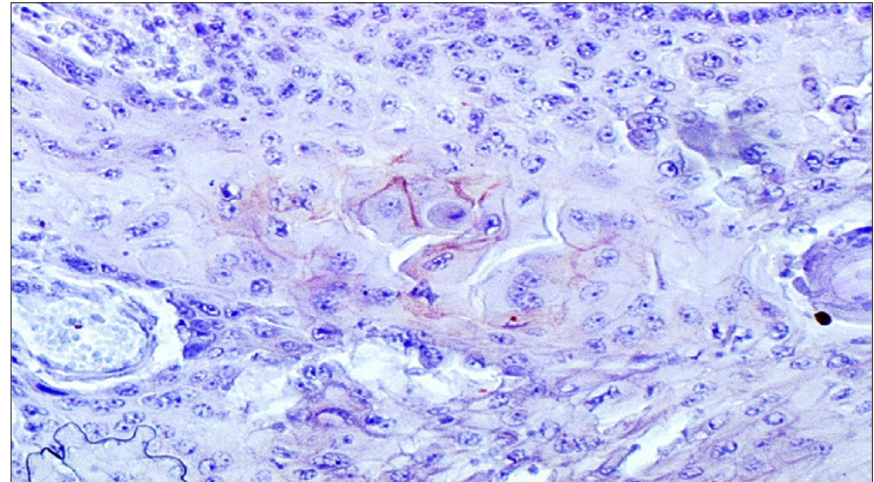

Figure 1. Negative immunoreactivity in the esophageal tumor area for C-erbB-2; Score 0 (x100)

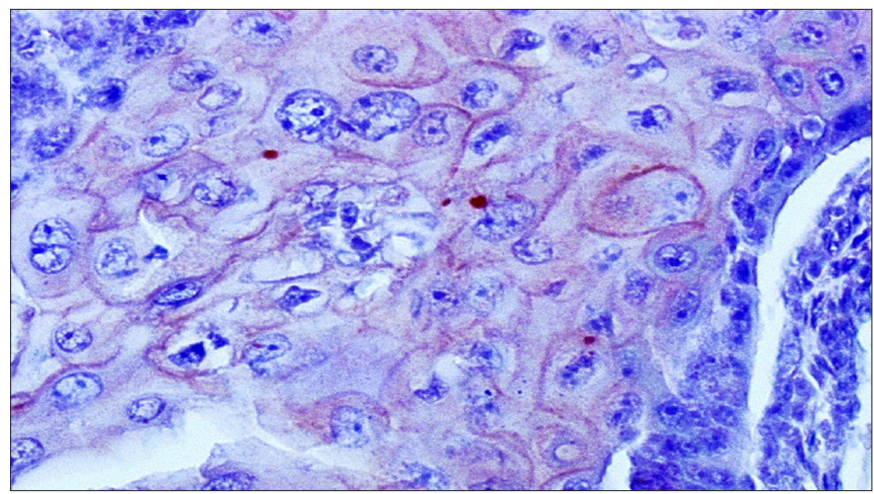

Figure 3. Weak complete membranous staining of more than $10 \%$ of the esophageal tumor area for C-erbB-2; Score 2 (x200)

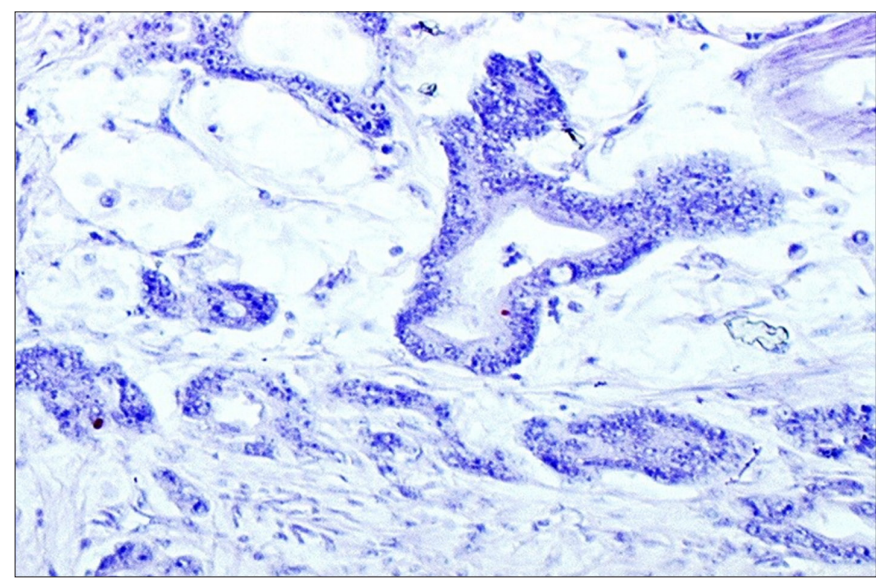

Figure 5. Negative immunoreactivity in the gastric tumor area for C-erbB-2; Score 0 (x100)

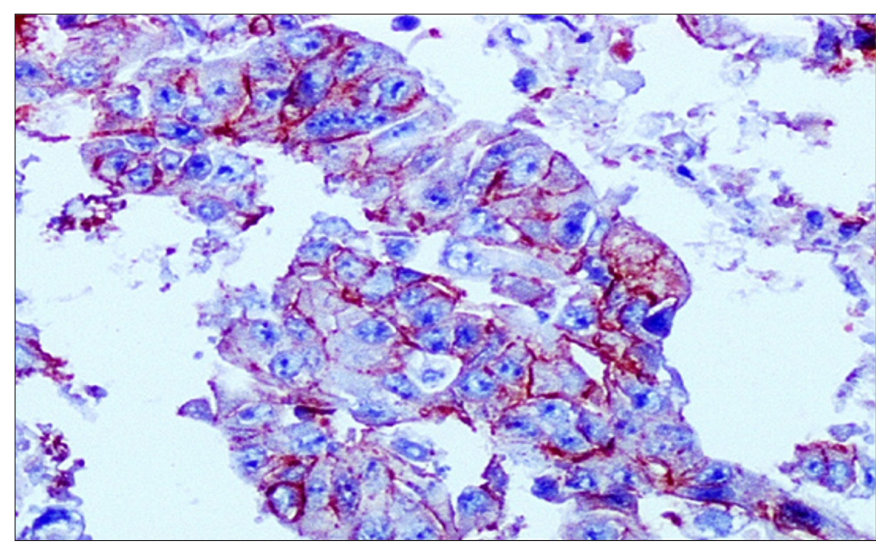

Figure 7. Weak complete membranous staining of more than $10 \%$ of the gastric tumor area for C-erbB-2; Score 2 (x200)

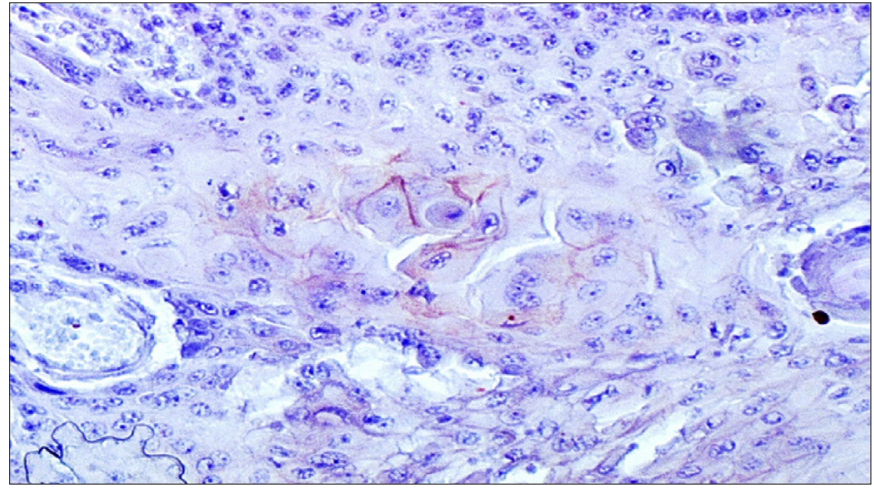

Figure 2. Incomplete membranous staining of more than $10 \%$ of the esophageal tumor area for C-erbB-2; Score 1 (x200)

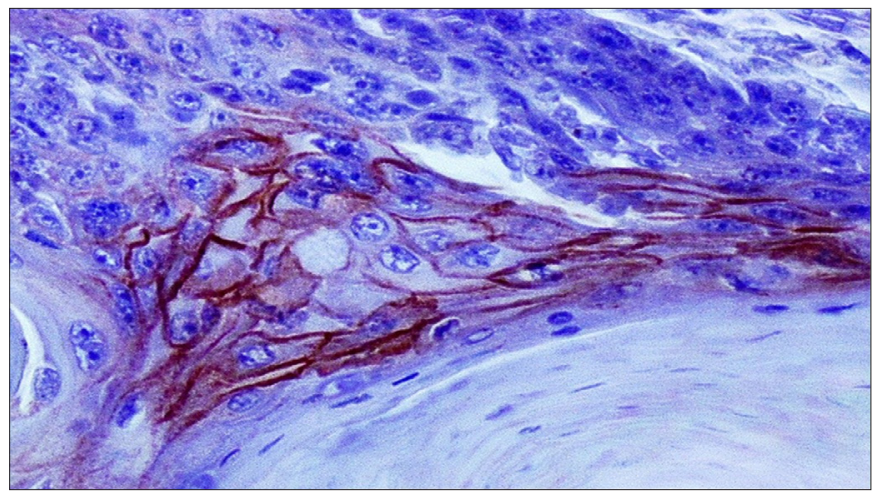

Figure 4. Intense complete membranous staining of more than $10 \%$ of the esophageal tumor area for C-erbB-2; Score 3 (x200)

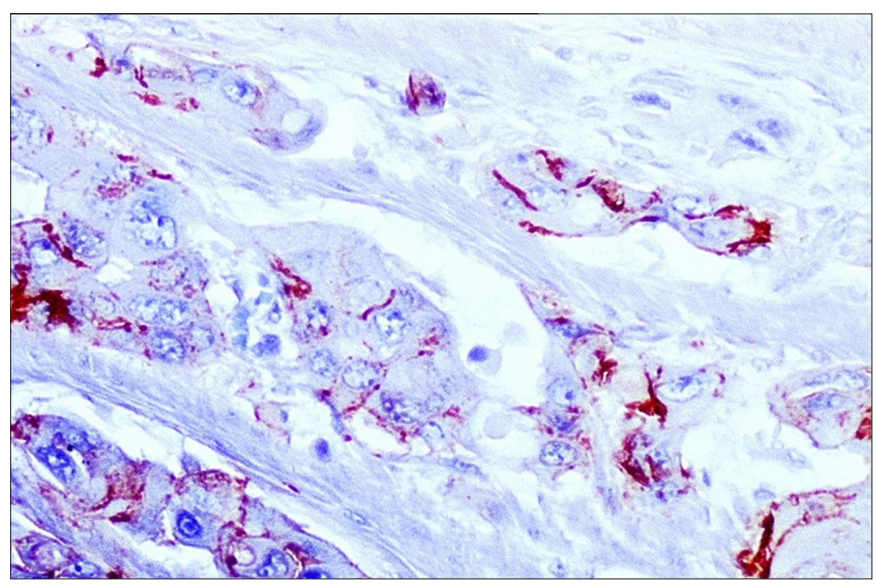

Figure 6. Incomplete membranous staining of more than $10 \%$ of the gastric tumor area for C-erbB-2; Score 1 (x200)

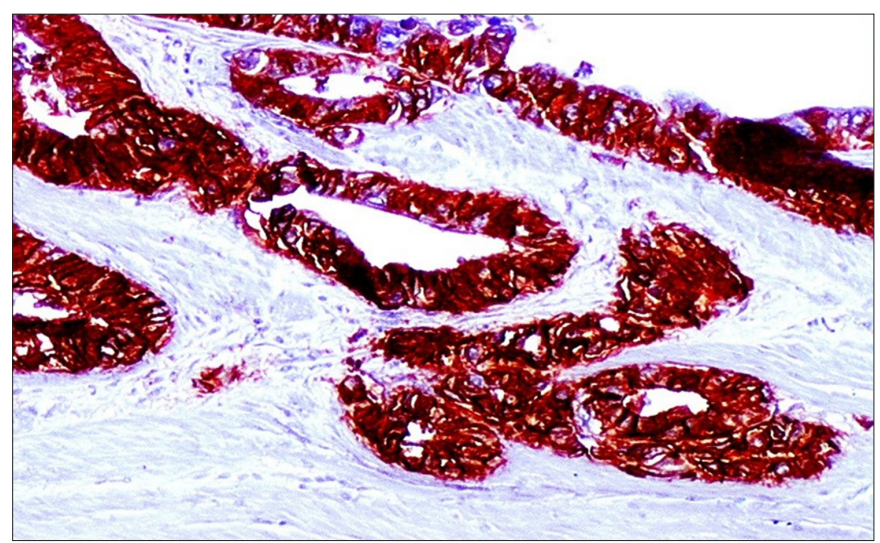

Figure 8. Intense complete membranous staining of more than $10 \%$ of the gastric tumor area for C-erbB-2; Score 3 (x200) 


\section{DISCUSSION}

C-erbB-2 overexpression was previously found to be associated with the stage and tumor grade in prostatic adenocarcinoma cases (15). In lung adenocarcinoma cases, the researchers also determined that patients with CerbB-2 overexpression had shorter survival compared to those not expressing this protein (16). C-erbB-2 overexpression and gene amplitude were discovered to be linked with poor prognosis in breast cancer patients (17). It was reported that C-erbB-2 overexpression occurred in $25-30 \%$ of breast carcinomas and that it was expressed at higher rates in ductal carcinoma in situ, especially in those with less differentiation, hormone receptor-negative, lymph node-positive, and increased proliferation (18). C-erbB-2 overexpression varied in immunohistochemical studies performed in esophageal cancers. Studies indicated that this rate ranged from $0 \%$ to $60 \%$. In our study, we detected that c-erbB-2 expression rates in gastric and esophageal cancers were similar to in breast cancer cases. In the study, we could not reach significant relationships between the intensity of c-erbB-2 staining and differentiation degree, lymph node involvement, and tumor invasion depth in gastric and esophageal cancers. C-erbB-2 positivity was found to be $24 \%$ in 25 cases with esophageal cancer. Possible reasons for obtaining different results in terms of C-erbB-2 positivity may depend on tumor histology, methodological differences, immunohistochemical methods, and tumor stages. The reason why other studies found the frequency of c-erbB-2 overexpression up to $60 \%$ may be due to the fact that cytoplasmic staining was also accepted as positive in these studies. However, cytoplasmic staining is accepted as non-specific in the contemporary c-erbB-2 scoring system, routinely used in breast carcinomas. In their immunohistochemical study, Lam et al. (22) investigated patients with esophageal squamous cell carcinoma retrospectively and found that c-erbB-2 overexpression was positive in 10 patients $(10 \%)$. Moreover, tumors with c-erbB-2 overexpression were found to be superficially well-differentiated tumors, and, therefore, it was concluded that c-erbB-2 overexpression was not associated with the biological behavior of the tumor. It was also suggested that c-erbB-2 overexpression might play an important role in identifying early-stage tumors.

The stage is an essential prognostic factor in esophageal cancer and provides the basis for treatment decisions. Studies comparing c-erbB-2 expression with TNM staging and other prognostic parameters have varied results. Sauter et al. (23) suggested that c-erbB-2 overexpression might disappear in the normal epithelium during tumor development in patients with esophageal adenocarcinoma. In a retrospective study with 62 cases,
Dursun et al. (24) found c-erbB-2 positivity in 11 (17.7\%) cases. In the study, c-erbB-2 positivity was found as $24.3 \%$ in intestinal-type carcinomas and $4.76 \%$ in diffuse-type carcinomas. In the same study, c-erbB-2 positivity was found in one of $9(11.1 \%)$ early-stage gastric cancer cases and $10(18.8 \%)$ of 53 advanced gastric cancer cases. In this study, we found no significant relationships between c-erbB-2 positivity and tumor invasion depth, lymph node metastasis, and tumor location, which led us to conclude that c-erbB-2 was not a prognostic marker.

We could also found no significant relationships between the c-erbB-2 staining intensity scores $(0,+1,+2,+3)$ and tumor invasion depth, lymph node metastasis, and the histopathological subtype. Despite the insignificant findings, all cases with c-erbB-2 positivity had lymph node involvement. The different results in other studies may have stemmed from different evaluations of immunohistochemical staining, sample differences, variations in the number of early and advanced gastric cancer cases, and the use of archive paraffin blocks. Tanner et al. (25) conducted a study, where 131 cases of gastric cancer and 100 cases with gastroesophageal junction tumors were included, and determined that there was c-erbB-2 positivity in 16 (12.2\%) of gastric cancer patients and 24 (24\%) of gastroesophageal junction tumors. They also found that c-erbB-2 positivity in gastric cancer cases was $21.5 \%$ in intestinal-type tumors and $2 \%$ in diffuse and mixed-type tumors. In the same study, cases with c-erbB-2 overexpression were shown to be associated with lower survival rates. In another study conducted to determine the frequency of c-erbB-2 expression in patients who underwent gastrectomy for gastric cancer, it was reported that c-erbB-2 expression could be used to differentiate a patient group who would benefit from targeted treatment approaches (26).

The limitations of our study are that it was conducted with few patients and the relationship between C-erbB-2 results and clinical data has not been researched.

\section{CONCLUSION}

In conclusion, larger and further studies are needed to more clearly observe the effect of C-erbB-2 expression on clinicopathological outcomes in gastric and esophageal cancers.

\section{ETHICAL DECLARATIONS}

Ethics Committee Approval: For the study, we obtained ethical approval from the Ethics Committee of School of Medicine, Atatürk University (Date: 12.15.2006, Session No: 8; Decision No: 40). 
Informed Consent: All patients signed the free and informed consent form.

Referee Evaluation Process: Externally peer-reviewed.

Conflict of Interest Statement: The authors have no conflicts of interest to declare.

Financial Disclosure: The authors declared that this study has received no financial support.

Author Contributions: All of the authors declare that they have all participated in the design, execution, and analysis of the paper, and that they have approved the final version.

\section{REFERENCES}

1. Earlam R, Cunha-Melo JR. Oesophageal squamous cell carcinoma I: a critical review of surgery. Br J Surg 1980; 67: 38190.

2. King RM, Pairolero PC, Trastek VF. Ivor Lewis esophagastrectomy for carcinoma of the esophagus: early and late functional results. Ann Thorac Surg 1987; 44: 119-22.

3. Klumpp T, Macdonald JS, Esophageal cancer: epidemiology and pathology. In Ahlgreen J, Macdonald J. (ed)s. Gastrointestinal Oncology. Philadelphia: JB Lippincott Company 1992; 71-80.

4. Kanserle Savaş Politikası ve Kanser Verileri (1995-1999), T.C Sağlık Bakanlığı Kanserle Savaş Dairesi Başkanlığı, Ankara 2002: 12-6.

5. Peters JH, De Meester TR, Essophagus and dipragmatic hernia Ed: Schwartz S1, Shires TG, Spencer FC, et al. Principles of Surgery. $7^{\text {th }}$ ed. McGraw-Hill, 1999:1081-180.

6. Becker KF, Keller G, Hoefler. The use of molecular biology in diagnosis and prognosis of gastric cancer. Surg Oncol 2000; 9: 5-11.

7. Truszkowski JA, Summers RW. Colorectal Neoplasms. Postgraduate Med 1996; 98: 20-5.

8. Başaran N.Tıbbi Genetik. Eskişehir, Bilim Teknik Yayınevi 1196: 357-68.

9. Sherman CD. Klinik Onkoloji. Türk Kanser Araştırma ve Savaş Kurumu yayınları, Ankara 1190: 3-9.

10. AOO Chan, SK Lam, KM Chu, et al. Soluble Ecadherin is a valid prognostic marker in gastric carcinoma. Gut 2001; 48: 808-11.

11. David N L, Klaus JL. Malignant: adenocarcinoma, stomach. In: Weidner N, Cote RJ, Suster S, Weiss LM, (ed)s. Modern Surgical Pathology Fist ed. Saunders; 2003: 672-80.

12. Yonemura Y, Ninomiya I, Yamaguchi A. Evalution of immünreactivity for c-erbB-2 protein as a marker of poor short term prognosis in gastric cancer. Cancer Res 1991; 51: 1034-8.

13. Flejou JF, Paraf F, Muzeau F, et al. Expression of c-erbB-2 oncogene product in Barrett's adenocarcinoma: Pathological and prognostic correlations. J Clin Pathol 1994; 47: 23-6.

14. Ueda M. New prognostic factors in patients with esophageal squamaus carcinoma. Gan To Kagaku Ryoho 1992; 19: 20-5.

15. Ross JS, Sheean C, Hayner Buchan AM, et al. HER-2/neu gene amplication status in prostate cancer by flourescence insutu hybridization. Hum Pathol 1997; 28: 827-33.

16. Kern JA, Schwartz DA, Nordberg JE. P185/neu expression in human lung adenocarcinomas predicts shortened survival. Cancer Res 1990; 50: 5184-9.

17. Ross JS, Fletcher JA. C-erbB-2 gene and protein in breast cancer. Am J Clin Pathol 1999; 112: 53-7.

18. Yarden Y. Biology of HER2 and it's importance in breast cancer. Oncology 2001; 61: 1-13.
19. Yoshida K, Kuniyasu H, Yasui W, et al. Expression of growth factors and their receptors in human esophageal carcinomas: Regulation of expression by epidermal growth factor and transforming growth factor alpha. J Cancer Res Clin Oncol 1993 119: 401-7.

20. Dreilich M, Wanders A, Brattstrom D. HER-2 overexpression $(3+)$ in patients with squamous cell esophageal carcinoma correlates with poorer survival. Dis Esophagus 2006;19: 224-31.

21. Suo Z, Su W, Holm R. Lack of expression of c-erbB-2 oncoprotein in human esophageal squamous cell carcinomas. Anticancer Res 1995; 15: 2797-8.

22. Lam KY, Tin L, Ma L. C-erbB-2 ptotein expression in a esophageal squamous epithelium from esophageal squamous cell carcinoma with special reference to histological grade of carcinoma and preinvasive lesions. Eur J Surg Oncol 1998; 24: 431-5.

23. Sauter ER, Keller SM, Erner S. HER-2/neu: A differentiation marker in adenocarcinoma of the esophagus. Cancer Lett 1993; 75: $41-4$.

24. Dursun A, Poyraz A, Çelik B, Akyol G. Expression of c-erbB-2 Oncoprotein in gastric carcinoma: correlation with histopathologic charesteristic s and analysis of Ki-67. Pathol Oncol Res 1999; 5: 104-6.

25. Tanner M, Hollmen M, Junntilla T, et al. Amplication of HER2 in gastric carcinoma: assosiacion with Topoisomerase 2 gene amplification, intestinal type, poor prognosis and sensitivity to transtuzumab. Ann Onc 2005; 16: 273-8.

26. Yıldırım S, Dandin O, Durmuş M, et al. C-erb-B2 (Her2/ neu) expression rate and its association with clinicopathologic parameters in gastric cancer. Int J Hematol Oncol 2012: 3: 156 62. 